\title{
CONTRIBUIÇÕES DO PRONAF PARA A AGRICULTURA FAMILIAR
}

\author{
Adriana Ribeiro Mota ${ }^{1}$
}

\section{RESUMO}

Este artigo relata a produção agrícola familiar, Programa Nacional de Apoio à Agricultura Familiar (PRONAF), no Brasil, no Nordeste e na Bahia, bem como discute questões referentes ao uso sustentável dos recursos naturais por esta modalidade de agricultura, proporcionando um equilíbrio social, econômico e ambiental de desenvolvimento. Demonstrar também as potencialidades, fundamentos legais e tecnologia empregada para a viabilização do processo produtivo. $\mathrm{O}$ objetivo geral deste estudo é identificar a contribuição do PRONAF para o fortalecimento da agricultura familiar no Brasil, e em especial na região Nordeste e estado da Bahia, bem como financiamento às políticas que visem à promoção do desenvolvimento rural sustentável.

Palavras-chave: Agricultura familiar. Pequeno produtor. Crédito rural. Desenvolvimento sustentável.

\section{ABSTRACT}

This article reports the family agricultural production, National Program of Support to family agriculture in Brazil, PRONAF-in the Northeast and in Bahia, as well as discusses issues relating to the sustainable use of natural resources by this mode of agriculture, providing a balance of social, economic and environmental development. Demonstrating the potential legal fundamentals and technology employed for the viability of the production process. The

${ }^{1}$ Graduada em Administração pela Universidade Estadual do Sudoeste da Bahia (UESB). E-mail: adrianna_motta@hotmail.com 
overall objective of this study is to identify the PRONAF's contribution to the strengthening of family agriculture in Brazil, and especially in the northeastern region and the State of Bahia, as well as funding to policies aimed at the promotion of sustainable rural development.

Keywords: Family farming. Small producer. Rural credit. Sustainable development.

\section{Introdução}

As novas tendências mundiais preconizadas na década de 90 exigiram uma maior organização dos trabalhadores rurais, em defesa de interesses coletivos. Dessa forma, a questão agrária se apresenta como um novo modelo de desenvolvimento agrícola. Nesse período ressurge com maior força a luta pela terra, mediante ações do Movimento dos Trabalhadores Rurais sem Terra (MST). Surge também a luta pela inclusão social e pela cidadania, apoiados pelas associações de pequenos produtores rurais, com prioridade para a agricultura familiar.

Partindo desse pressuposto, o governo Fernando Henrique Cardoso passa a priorizar projetos de desenvolvimento rural, com a organização dos pequenos produtores para gerar emprego e renda, o fomento à renda desconcentrada, a criação de ocupações produtivas para o produtor da agricultura familiar, a redução da migração campocidade e a minimização das desigualdades espaciais e sociais.

Este trabalho tem como objetivo identificar a contribuição que o Programa Nacional de Apoio a Agricultura Familiar (PRONAF) trouxe para a agricultura familiar por meio de financiamentos oficiais para a potencialização da referida atividade.

\section{A agricultura familiar e o PRONAF}

Após muitas mobilizações dos agricultores familiares, as quais tiveram início em 1992, e coordenadas pela Confederação Nacional dos Trabalhadores da Agricultura (Contag), foi criado o Programa de 
Valorização da Pequena Produção Rural (PROVAP). Esse programa tinha como principais reivindicações infraestrutura, meio ambiente e tecnologia rural. No entanto, tais exigências foram relegadas a segundo plano, pois entendia-se que não bastava problematizar as questões agrárias, também se fazia necessário dotar os agricultores familiares de condições materiais, mesmo que mínimas, visando proporcionar sustentação por meio de políticas diferenciadas. Dessa forma, era necessário priorizar o crédito rural (AVRITZER, 2002). Em 1996, esse programa foi totalmente reformulado, que deu origem ao PRONAF global, o qual priorizava apenas o crédito e o custeio, e ampliadas as suas ações, passou a financiar projetos de infraestrutura à capacitação.

O PRONAF tem como principal objetivo o desenvolvimento rural com ações que visem o aumento da capacidade produtiva para o financiamento, para a melhoria de infraestrutura, a capacitação de técnicos e agricultores familiares, e atividades agropecuárias por eles desenvolvidas.

Para pleitear crédito do PRONAF, o produtor deve apresentar declaração de aptidão ao programa, com o preenchimento dos seguintes requisitos: ser proprietário de gleba de terra inferior a 4 módulos fiscais (na região de Vitória da Conquista 140 ha); residir na propriedade ou em aglomerado rural próximo; explorar a atividade agrícola com mão de obra familiar, e, admitir eventualmente a contratação de serviços de terceiros, ter no mínimo $80 \%$ da renda bruta proveniente da atividade agropecuária.

A partir de 1997 houve um grande aumento da aplicação de recursos do programa para atender a tamanha demanda para o crédito rural, expressado pelo vasto número de contratos. Naquele período, o Conselho Monetário Nacional (CMN) adotou várias medidas, com vistas a estimular os agentes financeiros a apoiar o PRONAF, por outro lado, houve grande redução dos encargos financeiros incidentes sobre o crédito de custeio. Em 1995 os juros praticados na safra eram de 16\% ao ano, caindo para $12 \%$ na safra seguinte, sendo reduzido gradativamente em 1999 a taxa de $5.75 \%$ ao ano. 


\section{A importância da agricultura familiar no Brasil}

De acordo com o senso agropecuário de 1995/1996, havia no Brasil 4.859.732 estabelecimentos rurais, ocupando uma área de 353,6 milhões de hectares, dos quais 4.139.369 se caracterizavam como estabelecimentos familiares, preenchendo uma área de 107,8 milhões de hectares.

Os agricultores familiares representavam, naquela época, 85,2\% do total de estabelecimentos, que ocuparam $30 \%$ da área total, totalizando em 37.9\% do valor bruto da produção agropecuária nacional.

De acordo com informações do Ministério da Agricultura, a Radiobrás - Agência Brasil (CABRAL, 2007), no ano de 2006, o Programa Nacional de Agricultura Familiar beneficiou 1,9 milhões de famílias do qual o governo dispôs de 10 bilhões de reais para o financiamento de pequenos agricultores.

Nós acreditamos que o desenvolvimento do Brasil só irá acontecer se o governo começar a investir na agricultura familiar, que emprega mais de $80 \%$ dos trabalhadores do campo. Nós defendemos o fim da prática do agronegócio e dos grandes investimentos nas multinacionais que exploram os trabalhadores e que acabam com a biodiversidade (CABRAL apud MIRANDA, 2005, p. 1).

Segundo Evangelista et al. (2000), a agricultura familiar participa, na média, com $37,9 \%$ do valor bruto da produção realizada nos estabelecimentos familiares. As culturas de fumo, feijão e mandioca, além da pecuária de pequenos animais como suínos e aves poedeiras formam os sistemas de produção integrada e são praticamente exclusivas da agricultura familiar.

\section{Agricultura familiar no Nordeste}

$\mathrm{Na}$ região Nordeste do Brasil a grande maioria das propriedades rurais enquadram-se na categoria familiar, atingindo o percentual de 
$88,3 \%$ dos estabelecimentos rurais, os quais respondem por 43,5\% da área agricultável que gera aproximadamente 43,5\% da produção, obtendo $26,8 \%$ do financiamento total.

O Nordeste é a região do Brasil com maior percentual de estabelecimentos agrícolas familiares do país (49,7\%). Esses estabelecimentos são detentores de 31,6 \% de área de terra, entretanto, o valor bruto da produção é de apenas 16,7 \%, correspondendo de forma reduzida para a composição do processo produtivo.

O Nordeste é ainda a região que apresenta a menor área média na agricultura familiar (17 ha), e a segunda menor na agricultura patronal (269 ha), com valores bastante inferiores às médias do país (26 e 433 ha, respectivamente). De igual modo, a região apresenta as menores rendas médias totais e monetárias por estabelecimento, seja na agricultura familiar, seja na patronal. As rendas total e monetária da agricultura patronal nordeste são aproximadamente $52 \%$ das médias do país, já na agricultura familiar esse quadro é bem distinto: a renda total média do Nordeste é apenas 43\% da brasileira e a renda monetária média é ainda inferior somente 39\% (EVANGELISTA et al., 2000, p. 4).

Tabela 1 - Agricultores Familiares e Patronais - Renda Total (RT) e Renda Monetária $(\mathrm{RM})$ por estabelecimento (em R\$), segundo as regiões.

\begin{tabular}{l|c|c|c|c}
\hline \multirow{2}{*}{ REGIÃO } & \multicolumn{2}{|c|}{ FAMILIAR } & \multicolumn{2}{c}{ PATRONAL } \\
\cline { 2 - 5 } & RT/ Estab. & RM/Estab. & RT/ Patronal & RM/Patronal \\
\hline Nordeste & 1.159 & 696 & 9.891 & 8.467 \\
\hline Centro-oeste & 4.074 & 3.043 & 33.164 & 30.769 \\
\hline Norte & 2.904 & 1.935 & 11.883 & 9.691 \\
\hline Sudeste & 3.824 & 2.703 & 18.815 & 15.847 \\
\hline Sul & 5.152 & 3.315 & 28.158 & 23.355 \\
\hline Brasil & 2.717 & 1.783 & 19.085 & 1.400 \\
\hline
\end{tabular}


De 1999 a 2004, a região Sul recebeu entre 46 e 55\% do valor de recursos liberados, enquanto a região Nordeste encontra-se em segundo lugar, recebendo $24,62 \%$, tendo a sua participação reduzida ao longo desse período, na qual passa a receber apenas $16,9 \%$ em 2004, perdendo espaço para a região sudeste que foi contemplada com $17,56 \%$ no mesmo ano.

Com a queda da participação da referida região no total de recursos liberados, percebe-se que ela vem acompanhada de uma redução ainda maior na participação do crédito de investimento, recebendo em 2004 apenas $28,62 \%$ nesta modalidade.

A estrutura fundiária da agricultura familiar repete a concentração observada na agricultura do país de uma maneira geral. Conforme o quadro abaixo, 39,8\% dos estabelecimentos familiares possuem menos de 5 ha e, em conjunto, detém somente 3\% dos 107.768 ha reportados no quadro anterior. Em média, ocupam apenas 1,9 ha. No extremo oposto 5,9\% deles concentram 44,7\% daquela área com uma média de 67,8 ha.

Tabela 2 - Brasil Agricultura Familiar - Participação nos Estabelecimentos, na Área e Área Média, segundo os Grupos de Área Total (em ha)

\begin{tabular}{l|c|c|c}
\hline \multicolumn{1}{c|}{$\begin{array}{c}\text { GRUPOS DE } \\
\text { ÁREA TOTAL }\end{array}$} & ESTABELECIMENTOS & \% NA ÁREA & ÁREA MÉDIA \\
\hline Menos de 5 & 39,8 & 3,0 & 1,9 \\
\hline $\mathbf{5}$ a menos de $\mathbf{0 0}$ & 29,6 & 12,2 & 10,7 \\
\hline $\mathbf{2 0}$ a menos de 50 & 17,2 & 20,4 & 31,0 \\
\hline $\mathbf{5 0}$ a menos de $\mathbf{1 0 0}$ & 7,6 & 19, & 67,8 \\
\hline $\begin{array}{l}\mathbf{1 0 0} \text { ha a } \mathbf{1 5} \\
\text { módulos regionais }\end{array}$ & 5,9 & 44,7 & 198,0 \\
\hline $\begin{array}{l}\text { Área média dos } \\
\text { agricultores } \\
\text { familiares }\end{array}$ & \multicolumn{3}{|l}{} \\
\hline
\end{tabular}

Fonte: Brasil (2000).

\section{Agricultura familiar na Bahia}

De acordo com Cerqueira e Rocha apud Brasil (2000), 89,1\% dos estabelecimentos rurais baianos são caracterizados como familiares, 
ocupando $37,9 \%$ da área total, respondendo por 39,8\% do valor bruto da produção. $85 \%$ das pessoas envolvidas na agricultura baiana estão na produção familiar. De acordo com o referido autor apud Ribeiro (2002), a população de 95\% dos 150 municípios baianos mais pobres é predominantemente rural, revelando o elevado índice de pobreza localizado no meio agrário.

Com base nessas informações foi formulada uma política específica direcionada para esse segmento: o Programa Nacional de Agricultura Familiar (PRONAF).

Instituído em 1996, o PRONAF tem como principal objetivo desenvolver ações que proporcionam o fortalecimento da agricultura familiar mediante ao financiamento de custeio e capacitação de produtores rurais, assim como financiamento para implantação de projetos produtivos que visa o aumento da renda dos agricultores familiares, promovendo a fixação do homem no campo, evitando, assim, o êxodo rural.

Figura 1 - Produtores rurais de Montes Claros-MG beneficiários do crédito PRONAF

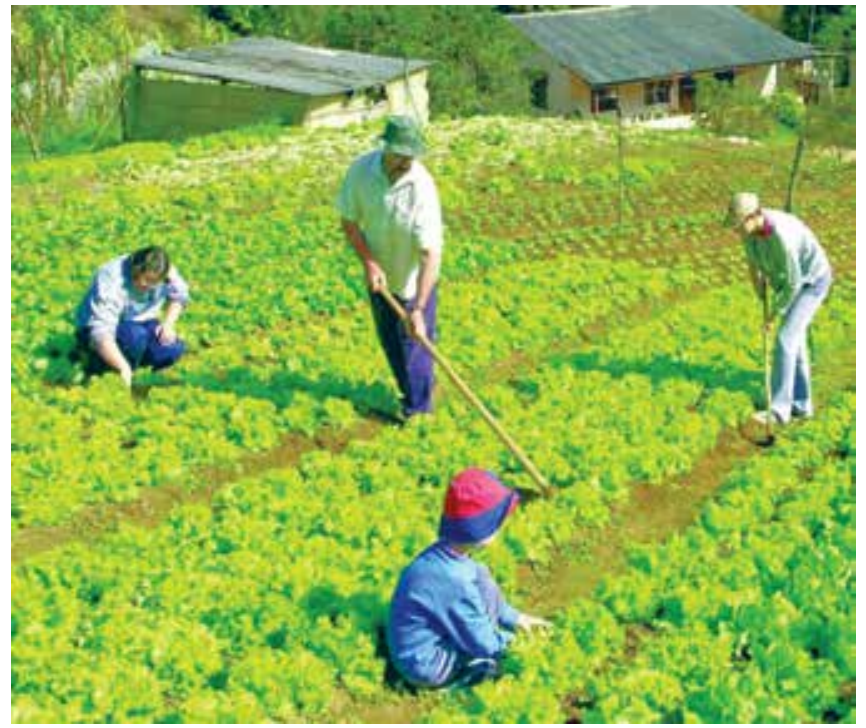

Fonte: Disponível em: <http://www.faes.org.br/noticias_detalhe.php?Cod_Noticia=1726> . 
Figura 2 - Agricultores do Espírito Santo beneficiários do crédito PRONAF

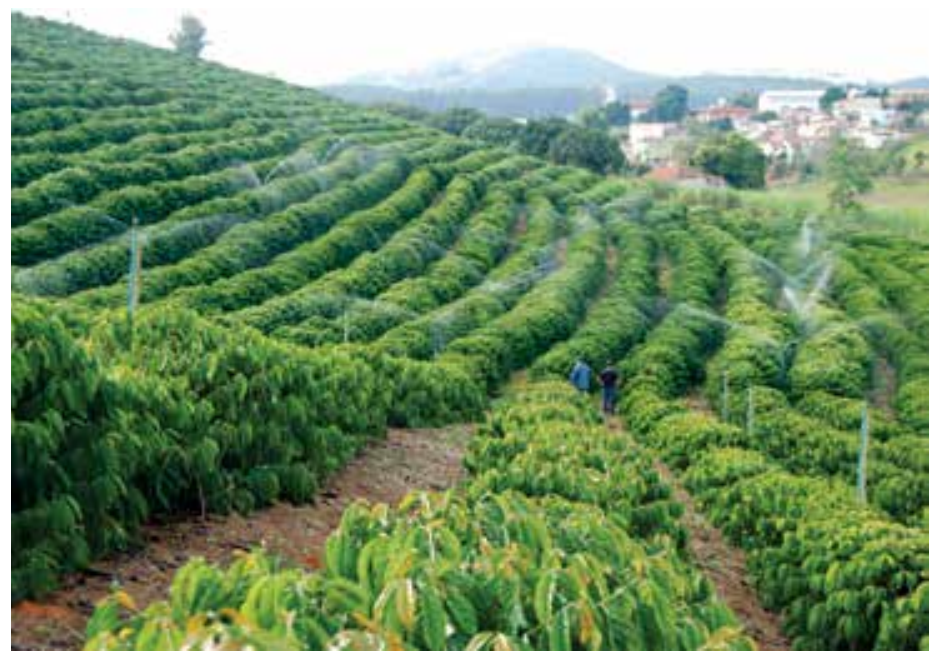

Fonte: Disponível em: <http://www.bandes.com.br/Site/Dinamico/Show?id=375>.

Para Cerqueira (2000), o crédito influencia de forma positiva na formação da renda e na melhoria dos indicadores sócio-econômicos, assim como os pronafianos obtém maiores resultados do que aqueles obtidos pelas famílias não pronafianas.

Os agricultores que obtiveram financiamento do PRONAF conseguiram uma renda média de $\mathrm{R} \$ 453,84 /$ ha, enquanto aqueles que não tiveram acesso ao crédito conseguiram rendimento muito inferior com apenas $\mathrm{R} \$ 254,43 /$ ha. Com base nesses dados, pode-se afirmar que se bem utilizados os recursos do PRONAF podem influenciar positivamente na produtividade dos agricultores familiares.

\section{Institucionalização da agricultura familiar no Brasil}

Apesar de praticada há muitos anos, a agricultura familiar foi institucionalizada apenas no ano de 2006 quando o presidente Luis Inácio Lula da Silva sancionou a Lei nº 11.326 de 24 de julho de 2006, na qual estabeleceu as diretrizes para a formulação da Política Nacional da Agricultura Familiar e Empreendimentos Familiares Rurais. De acordo 
com a referida Lei, considera-se agricultor e empreendedor familiar aquele que pratica atividade no meio rural, atendendo, simultaneamente, aos seguintes requisitos:

I - Não detenha, a qualquer título, área maior do que 4 módulos fiscais;

II - Utilize predominantemente mão de obra da própria família nas atividades econômicas do seu estabelecimento ou empreendimento;

III - Tenha renda familiar predominantemente originada de atividades econômicas vinculadas ao próprio estabelecimento ou empreendimento;

IV - Dirija seu estabelecimento ou empreendimento com sua família;

São também beneficiados desta Lei silvicultores, aqüiculturas, extrativistas e pescadores, desde que atendam todos os requisitos propostos pela mesma;

A Política Nacional da Agricultura Familiar e Empreendimentos Familiares Rurais observarão os princípios de descentralização, sustentabilidade social ambiental e econômica, equidade na aplicação das políticas, participação dos agricultores familiares na formulação e implementação dessas políticas.

\section{Agricultura familiar e desenvolvimento sustentável}

A preocupação com a sustentabilidade começou a ser discutida a partir da década de 70, com a conferência de Estocolmo - Suécia, onde foram discutidas maneiras de utilizar os recursos naturais de forma sustentável, visando o desenvolvimento social, ambiental e econômico.

O grande interesse pela agricultura familiar no Brasil motivou a formação de políticas públicas como o PRONAF e o Ministério do Desenvolvimento Agrário (MDA), além de revigorar a reforma agrária. A formulação dessas políticas atendeu às reivindicações das organizações de trabalhadores rurais e pressão dos movimentos sociais, fundamentada também com base científica e tecnológica. 
O modelo familiar se caracteriza por meio da condução do processo produtivo pelos proprietários, destacando a diversificação da produção, qualidade de vida, durabilidade e sustentabilidade na utilização dos recursos naturais, já que esses são finitos requerendo modelos racionais de uso e conservação. "A política Nacional da Agricultura Familiar e Empreendimentos Familiares Rurais, observará, dentre outros [...] sustentabilidade social, ambiental e econômica" (BRASIL, 2006).

A alternativa da agricultura familiar, além de produzir matériasprimas e alimentos, contribui com $80 \%$ da ocupação no meio rural, utilizando para isso técnicas ambientalmente menos impactantes, como diversificação de cultivos, menos utilização de insumos industrializados, e preservação do meio ambiente e do patrimônio genético.

O modelo familiar de agricultura vincula-se à ideia de desenvolvimento sustentável, pois proporciona uma distribuição equilibrada entre a população no território (em relação à patronal) estando associada à monocultura. Esses conceitos devem ser discutidos a fim de se chegar a consolidação do desenvolvimento sustentável.

De acordo com Altieri (2002), na agroecologia um programa de desenvolvimento rural tem como princípios:

- Segurança alimentar com valorização de produtos locais e conservação de germoplasma de variedades cultivadas localmente;

- Desempenhar e reavaliar o conhecimento das tecnologias no campo;

- Proporcionar a utilização eficiente dos recursos locais;

- Aumentar a diversidade vegetal e animal reduzindo os riscos;

- Diminuir o uso de insumos externos;

- Novas relações de mercado e organização social.

De acordo com Mello (2007 apud DENARDI et al., 2000), “[...] as bases ambientais de qualquer progresso futuro poderiam estar sendo comprometidas por crescimento econômico predatório de recursos naturais e altamente poluidores". 
A formação da agricultura familiar sustentável busca promover um desenvolvimento global agindo localmente, ou seja, um desenvolvimento endógeno. Dessa maneira, torna-se necessária a utilização mais eficiente e eficaz dos recursos naturais para que estes não sejam degradados, enfatizando a necessidade de sustentabilidade ecológica de longo prazo, para proporcionar o desenvolvimento das gerações atuais sem comprometer as futuras.

Mello (2007 apud ALTIERI, 2002), enfatiza que os sistemas de produção devem apresentar os seguintes preceitos:

- Reduzir o uso de energia e recursos e regular a entrada total de energia de modo que a relação entre saídas e entradas seja alta;

- Reduzir as perdas de nutrientes detendo a lixiviação, o escorrimento e a erosão, melhorar a reciclagem de nutrientes com o uso de leguminosas, adubação orgânica e compostos, e outros mecanismos eficientes de reciclagem;

- Incentivar a produção local de cultivos adaptados ao meio natural e socioeconômico;

- Sustentar um excedente líquido desejável, preservando os recursos naturais, isto é, minimizando a degradação do solo;

- Reduzir custos e aumentar a eficiência e a viabilidade econômica das pequenas e médias unidades de produção agrícola, promovendo, assim, um sistema agrícola potencialmente resiliente. Para Mello (2007, p. 5 apud CAPRA, 1996),

A mudança de paradigmas na agricultura requer novas maneiras de pensar e novos valores para que as tendências auto-afirmativas (pensamento racional, analítico, linear e reducionista) da cultura industrial ocidental sejam equilibradas com novas tendências do tipo integrativo (intuitivo, sintético, não linear e holístico). 
Figura 1 - Operacionalização do desenvolvimento rural sustentável.

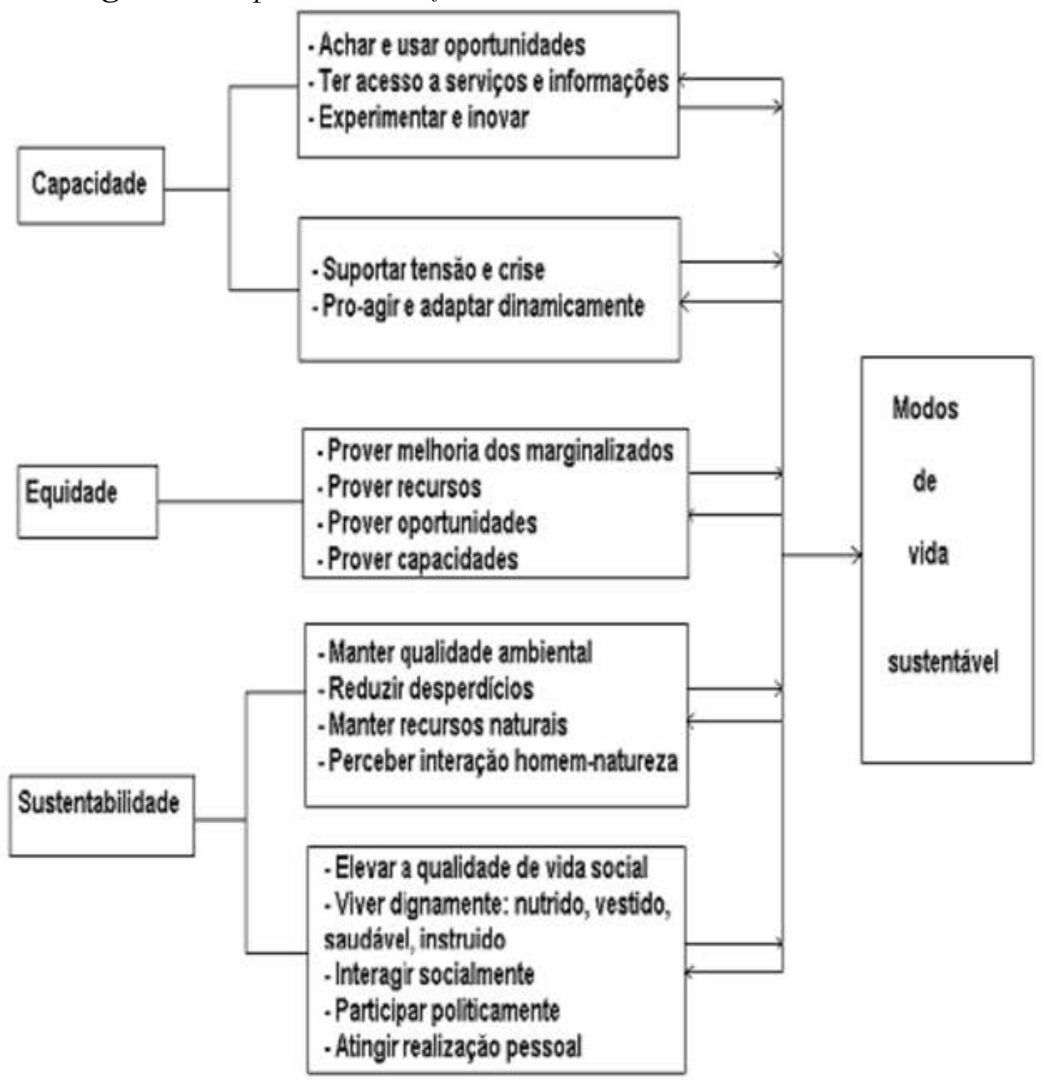

Fonte: Mello (2007 apud BICALHO, 1998, p. 78).

\section{Conclusão}

Os estudos realizados mostram a importância de um programa específico para o fomento à agricultura familiar. O PRONAF mostra o reconhecimento dos agricultores familiares como reais colaboradores no desenvolvimento sócio econômico do Brasil. Entretanto, a consecução dos objetivos depende de um efetivo acompanhamento, permitindo garantir a execução correta das ações propostas, assim como a aplicação adequada dos recursos disponíveis. 
Apesar de se apresentar como um dos elementos essenciais, o crédito disponibilizado isoladamente não garante a sobrevivência do empreendimento. Faz-se necessário um investimento em capacitação, que objetiva preparar o produtor para gerir de forma eficiente a sua propriedade, tornando-a autossustentável.

A referida pesquisa mostra ainda o Programa Nacional de Agricultura Familiar (PRONAF) como instrumento de inclusão social, haja vista que o mesmo possibilita aos agricultores familiares, os quais viviam marginalizados, o acesso ao crédito, e que após serem beneficiados passam a viver dignamente em suas propriedades, evitando dessa forma o êxodo rural.

\section{Referências}

ALTIERI, R. Agroecologia: bases científicas para uma agricultura sustentável. Guaíba-RS: Agropecuária, 2002.

AVRITZER, Leonardo. Sociedade civil e participação social no Brasil. Belo Horizonte: DCP UFMG, 2002.

BICALHO, Ana Maria de Souza Mello. Desenvolvimento rural sustentável e geografia agrária. In: ENCONTRO NACIONAL DE GEOGRAFIA AGRÁRIA, 14., 1998, Presidente Prudente, SP. Anais... Presidente Prudente, SP: UNESP, 1998.

BRASIL. Ministério do Desenvolvimento Agrário. Instituto Nacional de Colonização e Reforma Agrária (INCRA). Novo retrato da agricultura familiar. O Brasil redescoberto. Brasília: MDA/INCRA, 2000.

BRASIL. Lei $n^{\circ} 11.326$ de 24 de julho de 2006. Dispõe sobre a política nacional da agricultura familiar e empreendimentos familiares e rurais. Brasília, 2006.

CABRAL, Carolina. [Matéria]. Brasília: Radiobrás - Agência Brasil, 2007. Disponível em: <http://www.agenciabrasil.gov.br/noticias/2007/03/07/ materia. 2007-03-07.8819184815/view>. Acesso em: 11 dez. 2007. 
CERQUEIRA, Patrícia da Silva; ROCHA, Ana Georgina. A agricultura familiar e o PRONAF: elementos para uma discussão. Babia Análise \& Dados, Salvador, 2002. Disponível em: <http://www.sei.ba.gov. br/publicacoes/publicacoes_sei/bahia_analise/analise_dados/pdf/ retros2002/pag_105.pdf>. Acesso em: 11 dez. 2007.

DENARDI, R. A. et al. Fatores que afetam o desenvolvimento local em pequenos municípios do Paraná. Curitiba: EMATER/Paraná, 2000. Disponível em: <http://www.cria.org.br/gip/gipaf/itens/publ/artigos_trabalhos. html>. Acesso em: 5 set. 2007.

EVANGELISTA, Raimundo Francisco et al. A agricultura familiar no Brasil e no Nordeste. Equipe de estudos de sistemas agroindustriais e de turismo. INCRA. Escritório Técnico de Estudos Econômicos do Nordeste (ETENE). Banco do Nordeste do Brasil. [s. 1], 2000. Disponível em: <http://www.bnb.gov.br/content/Aplicacao/ETENE/Rede_ Irrigacao/Docs/Agricultura $\% 20$ Familiar $\% 20$ no $\% 20 \mathrm{Brasil} \% 20 \mathrm{e} \% 20$ no\%20Nordeste.PDF>. Acesso em: 11 dez. 2007.

MELLO, Roxane Lopes de; DIAS, Nelson Wellausen. Agricultura familiar e sustentabilidade social e ambiental. São Paulo, 2007. Disponível em: <http://www.inicepg.univap.br/cd/INIC_2008/anais/arquivosEPG/ EPG00978_01_A.pdf>. Acesso em: 11 dez. 2007.

MIRANDA, J. I. Fundamentos de sistemas de informações geográficas. Brasília: Embrapa Informação Tecnológica, 2005. 